\title{
Assessment and Management of the Dermatological Side Effects of Direct-Acting Antiviral Agent Groups Used in the Treatment of Hepatitis C: A Prospective Study
}

\author{
๑ Senay Agirgol, @ Muharrem Agirgol* \\ University of Health Sciences Turkey, Istanbul Haseki Training and Research Hospital, Clinic of Dermatology, Istanbul, Turkey \\ *University of Health Sciences Turkey, Istanbul Haseki Training and Research Hospital, Clinic of Pharmacy, Istanbul, Turkey
}

\section{Abstract}

Aim: As skin disorders may be observed with Hepatitis C, direct-acting antiviral drugs (DAA), dermatological side effects are also reported. The objective is to determine the dermatological side effects of DAA drugs.

Methods: A study was conducted with chronic hepatitis C patients who used Ombistavir/Paritaprevir/Ritonavir + Dasabuvir (Group 1), Sofosbuvir + Ledispavir (Group 2), and sofosbuvir (Group 3) and who supplied the drugs from our hospital. Skin examinations of the patients regarding dermatological side effects were conducted. Patients with dermatological side effects and treatment modalities were followed.

Results: One hundred twelve patients were using Group 1; 69 were using Group 2, 19 were using Group 3. All pruritus patients were in Group 1. It was detected in 56 of 200 patients (28\%). Pruritus was more prevalent in patients with diabetes mellitus, hypertension, and heart disease, and the drug could be tolerated in those with no additional systemic comorbidities. Thirty-one patients had renal failure, and 17 of them underwent renal transplantation, and the pruritus rate was high (57\%) in the chronic renal disease Group.

Conclusion: Pruritus is the most common side effect observed with DAA drugs used in treating hepatitis $C$ and elderly patients, and patients with comorbidity and renal transplantation are at high risk.

Keywords: Hepatitis C, antiviral agents, pruritus, cutaneous

\section{Introduction}

Hepatitis $\mathrm{C}$ virus (HCV) is a severe human pathogen with a prevalence of $0.2-4 \%$ in different countries. Every year, 3-4 million new hepatitis $C$ cases are detected, and it is thought that 185 million people in total are affected by HCV $(1,2)$. In Turkey, anti-HCV positivity is between 0.6$1.6 \%$, and chronic hepatitis is one of the most important causes of liver cirrhosis and hepatocellular carcinoma $(3,4)$. In Turkey, it is considered that there are 1-1.3 million people infected by HCV $(5,6)$. The objective of chronic hepatitis C treatment is to completely eradicate the virus. The frequent mutation and the availability of multiple genotypes of the virus make it challenging to find a vaccine, affecting treatment success. While peg-interferon and ribavirin are included in the classical treatment of chronic HCV, recently direct-acting antiviral (DAA) regimens for HCV infection has revolutionized its treatment by producing a sustained virologic response of more than $95 \%$ in the general population (7-9). Direct-acting antivirals Ombistavir/ Paritaprevir/Ritonavir + Dasabuvir are most frequently used in HCV genotype 1b Sofosbuvir + Ledipasvir are used in combination or Sofosbuvir is used alone (10).

There may be underlying dermatological diseases in hepatitis C patients, such as lichen planus, cryoglobulinemic vasculitis, that suggest hepatitis $C$ infection. Such diseases may light the HCV diagnosis, while it is reported that the dermatological disease regresses with HCV treatment $(11,12)$. Pruritus was reported to be $5 \cdot 1-58.4 \%$ in hepatitis $C$ patients (13-15). Pruritus is reported as the side effect of the DAA drugs used in the treatment of $\operatorname{HCV}(16,17)$. It is still a matter of discussion whether the pruritus arises from the HCV infection itself or the treatment (18). Direct-

Address for Correspondence: Senay Agirgol, University of Health Sciences Turkey, Istanbul Haseki Training and Research Hospital, Clinic of Dermatology, Istanbul, Turkey Phone: +90 5054987114 E-mail: senayagirgol@hotmail.com ORCID: orcid.org/0000-0002-8000-8883 Received: 12.11.2020 Accepted: 21.02.2021 
acting antivirals are safe drugs with a low side effect profile. The reported side effects of this Group of drugs are gastrointestinal side effects and pruritus (19). The safety and efficiency data regarding DAA drugs in chronic kidney disease (CKD) are not sufficient.

In this study, the demographical characteristics of the hepatitis $C$ patients using DAA and the drug side effects, and the dermatological side effects and their management in the patients with CKD and renal transplantation, as well as hepatitis $C$ patients using other DAA, were studied.

\section{Methods}

\section{Study Design}

This study was approved by the local ethics committee. A prospective study was conducted with adult chronic hepatitis C patients who used ObV/PTV/r + RBV, Sofosbuvir + Ledispavir, and Sofosbuvir and who supplied the drugs from our hospital. In our country, HCV drugs are distributed by certain designated pharmacies appointed by the government. The data of the patients who were diagnosed and had a drug report issued by more than 30 physicians and more than 10 sites, and who agreed to participate in the study was used. The patient data were obtained from the reports required to get the drug, and the study was completed with $200 \mathrm{HCV}$ patients between February 2017 and March 2018.

These patients who were using OBV/PTV/r + RBV (Group 1, $\mathrm{n}=112$ ), Sofosbuvir + Ledipasvir (Group 2, $\mathrm{n}=69$ ) and Sofosbuvir (Group 3, n=19) were recorded in 3 separate Groups.

The patients' demographical characteristics, HCV genotype, the pattern of contamination, presence of cirrhosis in the liver, comorbidities, and the drugs used for them were questioned. All skin, hair, and mucosal examinations of the patients with regards to dermatological side effects were conducted before the treatment started and on the 1st month of the treatment. The patients who attended the visits at least three times were included in the study. A patient with any dermatological side effect was followed up throughout the treatment, and treatment was applied for the side effect that developed. The HCV contamination pattern, systemic comorbidities, Ribavirin use, and, if any, the previous treatments, previous dermatological diseases of the patients were questioned and recorded.

\section{Statistical Analysis}

SPSS 15.0 for Windows was used for statistical analysis. The defining statistics are presented as numbers and percentages for categorical variables, and a mean, standard deviation (SD), and median are included for numeric variables. Comparison of numeric variables in two independent Groups was carried out using Student's t-test for normal distribution and the Mann-Whitney $U$ test for non-normal distribution. The relationships between numeric variables were examined using the Pearson correlation analysis when parametric test conditions were met and the Spearmen correlation analysis when these conditions were not met. Statistical alpha significance level was assumed to be $p<0.05$.

\section{Results}

The female gender was dominant among $200 \mathrm{HCV}$ patients in the study $(n=113,56.5 \%)$. The ages of the patients were between 19-92 years. (Avr: 59.2 \pm 13.7 ) While in most patients, the mode of contamination was unknown, dialysis was the second mode of contamination for $\mathrm{HCV}$, followed by childbirth, surgeries, dental treatment, and one of the patients was contaminated by hair transplantation. Most of the patients were HCV genotype $1 \mathrm{~b}(82 \%)$, and approximately $70 \%$ of the patients were firstly treated by DAA drugs.

\section{Antiviral Treatment and Chronic HCV}

One hundred twelve patients were using Group 1. 69 patients were using Group 2. 19 patients were using Group 3. 158 patients were non-cirrhotic, while eight patients were decompensated cirrhotic. $60 \%$ of the patients had comorbidities such as diabetes, coronary failure, asthmaCOPD. Thirty-one patients had renal failure, and 17 of them underwent renal transplantation. Fourteen CKD patients were under dialysis treatment. Eight of CKD patients had pruritus (Table 1). In this study, 14 CKD patients had hemodialysis $n=14$, and $57 \%$ developed pruritus. While no side effects were observed in 2 patients who had liver transplantation, pruritus developed in 2 of 17 patients with renal transplantation, and others managed to complete the treatment without problems.

The great majority of the patients were using Group 1 drugs, and the most frequent side effect was pruritus. Almost all of the patients who developed pruritus were in this Group. The intensified pruritus in patients who previously had pruritus was recorded as a side effect. The patients whose pruritus was stable were not evaluated as a drug side effect. Pruritus regressed in many of the patients through symptomatic treatment. One of the patients developed nodular prurigo, and the lesions were regressed with topical corticosteroid ointment and antihistaminic tablets. When the patients who previously had xerosis were excluded, two patients had notable xerosis. The other concomitant dermatological diseases were at ratios similar to society. While pruritus was more prevalent in patients with diabetes mellitus (DM), hypertension ( $\mathrm{HT})$, and heart disease, the drug could be tolerated in those with no additional systemic comorbidities (Table 2). 


\section{Discussion}

HCV is a ribonucleic acid virus from the Flaviviridae family with a single positive chain. As the virus is not entirely visualized, its structure is not clearly known, and its classification was made based on its genomic differences. Six genotypes (GT1-6), and each one was typed as several subgroups. The most frequent genotype 1 (GT1) and genotype $1 \mathrm{a}$ and genotype $1 \mathrm{~b}$ subgroups are responsible for most GT1 infections worldwide $(6,20)$. In our study,

Table 1. Demographic characteristics of the patients, mode of contamination, concomitant systemic diseases, other systemic disease and ribavirin usage

\begin{tabular}{|c|c|c|}
\hline & & $n \%$ \\
\hline \multirow{2}{*}{ Gender } & Male & $87(43.5)$ \\
\hline & Female & $113(56.5)$ \\
\hline Age (years) & - & $\begin{array}{l}59.2 \pm 13.7 \\
(19-92)\end{array}$ \\
\hline Disease time (year) & - & $\begin{array}{l}7.0 \pm 6.2(0.5- \\
35)\end{array}$ \\
\hline \multirow{3}{*}{ Diagnosis } & $\begin{array}{l}\text { Decompensated } \\
\text { cirrhotic }\end{array}$ & $8(4.0)$ \\
\hline & Compensated cirrhotic & $34(17.0)$ \\
\hline & Cirrhotic & 15879.0 \\
\hline \multirow{6}{*}{ Contamitation type } & Unknown & $139(69.5)$ \\
\hline & Surgery & $7(3.5)$ \\
\hline & Dialysis & $41(20.5)$ \\
\hline & Child-birth & $11(5.5)$ \\
\hline & Hair transplantation & $1(0.5)$ \\
\hline & Drug-abuse & $1(0.5)$ \\
\hline \multirow{6}{*}{ HCV Genotype } & $1 \mathrm{a}$ & $18(9.0)$ \\
\hline & $1 b$ & $164(82.0)$ \\
\hline & 2 & $1(0.5)$ \\
\hline & 3 & $5(2.5)$ \\
\hline & 3a & $11(5.5)$ \\
\hline & $3 b$ & $1(0.5)$ \\
\hline \multirow{3}{*}{ Concomitant disease } & Chronic renal failure & $14(7.0)$ \\
\hline & Renal transplantation & $17(8.5)$ \\
\hline & Liver transplantation & $2(1.0)$ \\
\hline \multirow{7}{*}{ Other systemic disease } & - & $128(64.0)$ \\
\hline & HT & $90(45.0)$ \\
\hline & DM & $33(16.5)$ \\
\hline & COPD-ASTHMA & $19(9.5)$ \\
\hline & $\mathrm{CHF}$ & $2(1)$ \\
\hline & CAD & $6(3)$ \\
\hline & Other & $18(9)$ \\
\hline Ribavirin use & - & $58(29)$ \\
\hline Treatment useage before & - & $57(28.5)$ \\
\hline \multicolumn{3}{|c|}{$\begin{array}{l}\text { HT: Hypertension, DM: Diabetes mellitus COPD: Chronic obstructive pulmonary } \\
\text { disease, CHF: Congestive heart failure, CAD: Coronary artery disease, HCV: } \\
\text { Hepatitis C virus }\end{array}$} \\
\hline
\end{tabular}

genotype $1 \mathrm{~b}$ was the most frequent type, and this was compliant with the studies conducted in the same city and with the literature $(4,6,21)$.

Hepatitis C patients may have some dermatological symptoms $(12,15,22)$. and these are reported in the previous studies $(12,23)$. Mix cryoglobulinemia, porphyria cutanea tarda, lichen planus, pruritus are among the diseases reported $(17,24)$. The association of lichen planus and hepatitis $C$ is being examined. Lichen patients were reported to be treated with DAA (25). In this study, no lichen disease was detected. The dermatological findings such as atopic eczema, psoriasis, acne rosacea, seborrheic dermatitis, and acne observed within the study scope were similar to society.

Pruritus is seen in chronic liver diseases and affects the quality of life (26). Although the cause of the pruritus development in such patients has not been yet determined, studies were conducted regarding the fibrosis in the liver, high enzyme levels, or bilirubin levels. Pruritus is also reported to have developed during the treatment of HCV patients $(17,26,27)$.

DAA is effectively used in the treatment of HCV. In a recent review, the side effects of DAA were reviewed (28). In the studies conducted at advanced ages, it was found to be effective and reliable (29). In the study by Tachi et al. (30) it was reported that $10 \%$ of the patients had developed pruritus after DAA use, while some of the patients who had pruritus before treatment reported regression with the treatment. In this study, the pruritus ratio after DAA treatment resulted in $28 \%$. This ratio was higher when compared to the literature. The reason for the

\begin{tabular}{|c|c|c|}
\hline & & $\mathbf{n} \%$ \\
\hline \multirow{3}{*}{ DAA } & Group 1 & $112(56)$ \\
\hline & Group 2 & $69(34.5)$ \\
\hline & Group 3 & $19(9.5)$ \\
\hline Treated cures & - & $2.7 \pm 1.2(1-7)$ \\
\hline \multirow{3}{*}{ Skin side effects } & Pruritus & $56(28)$ \\
\hline & Xerosis & $2(1)$ \\
\hline & Conjunctivitis & $1(0.5)$ \\
\hline \multirow{9}{*}{ Concomitant skin disease } & Xerosis & $11(5.5)$ \\
\hline & Dermatitis & $13(5.5)$ \\
\hline & Psoriasis & $6(3.0)$ \\
\hline & Pruritus & $1(0.5)$ \\
\hline & Acne & $1(0.5)$ \\
\hline & Atopic dermatitis & $1(0.5)$ \\
\hline & Acne rosacea & $1(0.5)$ \\
\hline & Vitiligo & $1(0.5)$ \\
\hline & Seborrheic dermatitis & $1(0.5)$ \\
\hline \multicolumn{3}{|c|}{$\begin{array}{l}\text { Group 1: Ombistavir/Paritaprevir/Ritonavir + Dasabuvir. Group 2: Sofosbuvir and } \\
\text { ledispavir. Group 3: Sofosbuvir, DAA: Direct-acting antiviral drugs, HCV: Hepatitis } \\
\text { C virus }\end{array}$} \\
\hline
\end{tabular}


different side effects reporting may be the patients failed to report due to mild progress or due to the humudity. The majority of the patients had comorbidities and the inclusion of CKD patients in the group, and the majority of the patients were 65 years or above. Most of the patients within the Group were 65 years or above. The ratio of pruritus development in patients who were under 65 years was $18.1 \%$. Villani et al. (31) reported that pruritus, rash, and photosensitivity were slightly high in patients over 65 years of age. No examinations were made on the patients in our study. Therefore, no comments were made regarding the liver functions and bilirubin levels. There was no statistically significant difference between cirrhotic and non-cirrhotic groups.

Sofosbuvir was used alone in 19 patients and combination in 69 patients. Those who used this group of the drug did not develop pruritus (32).

In hemodialysis patients, the most frequent cause of the liver disease is HCV infection, and the anti-HCV ratio varies between 21.3 and 41.5. DAA was safely used in renal transplantation patients, and no side effects were observed in the patients $(7,33)$. Although it was possible to observe systemic gastrointestinal side effects in CKD and renal transplantation patients, all patients managed to complete the DAA treatment (34). The authors reported that it is safe and relatively well tolerated in advanced renal failure and that no of-related specific toxicity was detected. The high ratio may be due to the absence of continuity in drug elimination in CKD patients. The side effects of renal transplantation patients matched the literature. The persistent pruritus following the skin moisturizing for xerosis in patients with renal failure and the pruritus regressed after discontinuing DAA were considered drug side effects.

Ribavirin was used as a supplement to the treatment (35). In the previous studies, it was reported that ribavirin might be a factor, and it has dermatological side effects by $10 \%$, such as xerosis, alopecia, eczema, psoriasis $(16,36)$. No difference was detected in terms of pruritus between the use of ribavirin or not.

Intravenous narcotic use is an essential mode of contamination for the virus infection. In our study, the use of narcotics was made through patient declaration. One patient continued using narcotics, and that he did not have dermatological side effects. No differences in dermatological side effects were detected between the patients experienced in terms of treatment and those using for the first time.

When asked about the drug's positive effect, almost all patients using DAA stated that they did not have flu. Since there is no pandemic during the study, and it is not included in planning at the beginning of the study, no clear data can be given. Data on the course of Coronavirus disease-2019 (COVID-19) patients in HCV patients using DAA may contribute to these drugs' COVID-19 effect. Currently, remdesivir has received fluorescein diacetate approval for COVID-19.

In dermatological side effects developed with DAA, the symptoms were minimized with good skincare, and the treatment was accomplished. Emollient creams, pomades with corticosteroid for short term use in patients with severe pruritus, and antihistamines were added to the treatment.

\section{Study Limitations}

The deficits of this study were the absence of liver function tests of the patients, and the viral charge at the beginning and the post-treatment efficiency were not evaluated. The correlation between treatment success and side effects was not evaluated.

\section{Conclusions}

Pruritus and skin rash are common with DAA drugs used in HCV treatment. Elderly patients with comorbidities such as DM and HT may be under at more risk, and pruritus complaints may be controlled with efficient skincare in such patients. The detailed examinations to be conducted in patients with pruritus and dermatological side effects may contribute to the explanation of the etiology.

\section{Authorship Contributions}

Concept: S.A., M.A., Design: S.A., M.A., Data Collection or Processing: S.A., M.A., Analysis or Interpretation: S.A., M.A., Literature Search: S.A., M.A., Writing: S.A., M.A.,

Conflict of Interest: No conflict of interest was declared by the authors.

Financial Disclosure: The authors declared that this study received no financial support.

\section{References}

1. Lozano R, Naghavi M, Foreman K, et al. Global and regional mortality from 235 causes of death for 20 age groups in 1990 and 2010: a systematic analysis for the Global Burden of Disease Study 2010. Lancet 2012;380:2095-128.

2. Tsukuma H, Hiyama T, Tanaka S, et al. Risk factors for hepatocellular carcinoma among patients with chronic liver disease. N Engl J Med 1993;328:1797-801.

3. Arends JE, Kracht PA, Hoepelman Al; European Study Group for Viral Hepatitis (ESGVH). Performance of hepatitis $C$ virus (HCV) direct-acting antivirals in clinical trials and daily practice. Clin Microbiol Infect 2016;22:846-52. 
4. Suntur BM, Kaya H, Eker HBŞ, Kara B, Bozok T, Unal N. A cross-sectional study of real life data of HCV from Turkey south region. J Infect Dev Ctries 2020;14:380-6.

5. Kirdar S, Aydin N, Tiryaki Y, Ertugrul B, Coskun A, Bilgen M. Dynamics of HCV epidemiology in Aydin province of Turkey and the associated factors. APMIS 2018;126:109-13.

6. Çetin Duran A, Kaya Çetinkaya Ö, Sayıner AA, Şeydaoğlu G, Özkarataş E, Abacıoğlu H. Changes on Hepatitis C virus genotype distribution in Western Turkey: Evaluation of twelve-year data. Turk J Gastroenterol 2020;31:128-35.

7. Goetsch MR, Tamhane A, Varshney M, et al. Direct-Acting Antivirals in Kidney Transplant Patients: Successful Hepatitis C Treatment and Short-Term Reduction in Urinary Protein/ Creatinine Ratios. Pathog Immun 2017;2:366-75.

8. Mikolas LA, Jacques K, Huq M, Krasner C, Mambourg SE. Utilizing Clinical Pharmacist Specialist to Manage Hepatitis C Virus Patients on Direct-Acting Antiviral Therapy. J Pharm Pract 2019;32:655-63.

9. Bourlière $M$, Pietri $O$. Hepatitis $C$ virus therapy: No one will be left behind. Int J Antimicrob Agents 2019;53:755-60.

10. Piecha F, Gänßler JM, Ozga AK, et al. Treatment and retreatment results of HCV patients in the DAA era. PLoS One. 2020;15:0232773.

11. Chung CM, Nunley JR. Overview of hepatitis $C$ and skin. Dermatol Nurs 2006;18:425-30.

12. Cacoub P, Bourlière $M$, Lübbe J, et al. Dermatological side effects of hepatitis $C$ and its treatment: patient management in the era of direct-acting antivirals. J Hepatol 2012;56:45563.

13. Cheung AC, Patel H, Meza-Cardona J, Cino M, Sockalingam S, Hirschfield GM. Factors that Influence Health-Related Quality of Life in Patients with Primary Sclerosing Cholangitis. Dig Dis Sci 2016;61:1692-9.

14. Gutteling JJ, de Man RA, Busschbach JJ, Darlington AS. Overview of research on health-related quality of life in patients with chronic liver disease. Neth J Med 2007;65:22734.

15. Dervis E, Serez K. The prevalence of dermatologic manifestations related to chronic hepatitis $C$ virus infection in a study from a single center in Turkey. Acta Dermatovenerol Alp Pannonica Adriat 2005;14:93-8.

16. Stauber RE, Fauler G, Rainer F, et al. Anti-HCV treatment with ombitasvir/paritaprevir/ritonavir \pm dasabuvir is associated with increased bile acid levels and pruritus. Wien Klin Wochenschr 2017;129:848-51.

17. Tawfik YM, Hassany SM, Badran AY, El-Gazzar AF, Alemam MF, Sayed DS. Hepatitis C virus associated skin manifestations in upper Egypt: Before and after direct acting antiviral treatment. Dermatol Ther 2020;33:14365.

18. Rebora A. Skin diseases associated with hepatitis $C$ virus: facts and controversies. Clin Dermatol 2010;28:489-96.
19. Ferreira VL, Borba $\mathrm{HHL}$, Wiens $A$, et al. Effectiveness and tolerability of direct-acting antivirals for chronic hepatitis C patients in a Southern state of Brazil. Braz J Infect Dis 2018;22:186-92.

20. Akkarathamrongsin S, Payungporn S, Thong VD, et al. Early viral kinetics during hepatitis $C$ virus genotype 6 treatment according to IL28B polymorphisms. World J Gastroenterol 2014;20:10599-605.

21. Karabulut N, Alacam S, Yolcu A, Onel M, Agacfidan A. Distribution of hepatitis $C$ virus genotypes in Istanbul, Turkey. Indian J Med Microbiol 2018;36:192-6.

22. Cozzani E, Herzum A, Burlando M, Parodi A. Cutaneous manifestations of HAV, HBV, HCV. G Ital Dermatol Venereol 2019 Dec 4.

23. Patel P, Malik K, Krishnamurthy K. Cutaneous Adverse Events in Chronic Hepatitis C Patients Treated With New DirectActing Antivirals: A Systematic Review and Meta-Analysis. J Cutan Med Surg 2016;20:58-66.

24. Fuentes A, Mardones C, Burgos PI. Understanding the Cryoglobulinemias. Curr Rheumatol Rep 2019;21:60.

25. Nagao Y, Kimura K, Kawahigashi Y, Sata M. Successful Treatment of Hepatitis C Virus-associated Oral Lichen Planus by Interferon-free Therapy with Direct-acting Antivirals. Clin Transl Gastroenterol 2016;7:179.

26. Tachi Y, Hirai T, Kojima Y, et al. Predictive ability of shear wave elastography for pruritus in chronic hepatitis $C$ patients with sustained virological response. Eur J Gastroenterol Hepatol 2018;3:1066-72.

27. Oeda S, Takahashi H, Yoshida H, et al. Prevalence of pruritus in patients with chronic liver disease: A multicenter study. Hepatol Res 2018;48:252-62.

28. Surjadi M. Chronic Hepatitis C Screening, Evaluation, and Treatment Update in the Age of Direct-Acting Antivirals. Workplace Health Saf 2018;66:302-9.

29. Conti F, Brillanti S, Buonfiglioli F, et al. Safety and efficacy of direct-acting antivirals for the treatment of chronic hepatitis $C$ in a real-world population aged 65 years and older. J Viral Hepat 2017;24:454-63.

30. Tachi Y, Hirai T, Kojima Y, et al. Predictive ability of shear wave elastography for pruritus in chronic hepatitis $C$ patients with sustained virological response. Eur J Gastroenterol Hepatol 2018;30:1066-72.

31. Villani R, Monami M, Di Cosimo F, et al. Direct-acting antivirals for HCV treatment in older patients: A systematic review and meta-analysis. J Viral Hepat 2019;26:1249-56.

32. Liu CH, Su TH, Liu CJ, et al. Sofosbuvir-based direct acting antiviral therapies for patients with hepatitis $C$ virus genotype 2 infection. J Gastroenterol Hepatol 2019;34:1620-5.

33. Ishida K, Shimakami T, Kaneko S. [The use of direct-acting antivirals in the treatment of elderly patients with hepatitis 
C Virus infection]. Nihon Ronen Igakkai Zasshi 2017;54:37580 .

34. Ko SY, Choe WH. Management of hepatitis C viral infection in chronic kidney disease patients on hemodialysis in the era of direct-acting antivirals. Clin Mol Hepatol 2018;24:351-7.

35. Waldenström J, Lagging M. Editorial: ribavirin continues to play a role in treatment with direct-acting antivirals for hepatitis $C$ virus-infected patients with decompensated cirrhosis. Aliment Pharmacol Ther 2017;46:1115-6.

36. Brok J, Gluud LL, Gluud C. Ribavirin plus interferon versus interferon for chronic hepatitis C. Cochrane Database Syst Rev 2010;(1):005445. 